\title{
Resenha do Livro "Neither Physics nor Chemistry: a History of Quantum Chemistry"
}

por Itamar Borges Jr.

reconhecimento

da

importância da química quântica na formação do químico no Brasil é crescente e revelado pela criação de cadeiras de graduação e pósgraduação inteiramente dedicadas a ela.

É sintomático que o Simpósio Brasileiro de Química Téorica (SBQT), criado há mais de 30 anos e praticamente todo dedicado à química quântica, tenha sido coordenado por químicos e físicos em suas edições bianuais. Desde 2001, em sucessão ao papel do Journal of Theoretical Chemistry - THEOCHEM iniciado em 1991 até aquela altura, artigos completos baseados nos trabalhos apresentados no SBQT têm sido publicados no International Journal of Quantum Chemistry em edições especiais dedicadas ao Simpósio, o que filia o Brasil ao mainstream da química quântica internacional (link para todas as edições em http://www.sbqt.net/pt/proceedings. htm). No 16o SBQT, realizado em novembro 2011 em Ouro Preto, Minas Gerais, quase 500 participantes em sua grande maioria brasileiros apresentaram seus trabalhos na área.

E o que seria a química quântica? Uma subdisciplina legítima da química? Ou seria apenas uma subárea marginal e aplicada da física? Quais são as origens e os personagens criadores desta disciplina que combina física, química e matemática? Como surgiram os ubíquos modelos de orbitais moleculares e da ressonância da ligação química, apresentados aos estudantes desde o Ensino Médio? Quem são os principais personagens e os embates políticos e pessoais que ajudaram a estabelecer a química quântica como ciência ao longo do século 20 ?
Cesar Lattes, um dos maiores cientistas brasileiros, reconhecido tanto pelas suas descobertas como pela dedicação à institucionalização da ciência nacional, considerava que a "história é a mais importante das ciências. Sem ela, não há realidade objetiva". ${ }^{1}$ Portanto, fazendo coro ao importante conselho do mestre, é fundamental incluir na formação de cientistas de qualquer área uma sólida base histórica. Uma importante contribuição para a história da química que busca respostas às perguntas do parágrafo anterior foi lançada agora em 2012 pela MIT Press.

Essa contribuição é o fascinante livro Neither Physics nor Chemistry: a History of Quantum Chemistry (Nem Física nem Química: uma História da Química Quântica). Os autores, Kostas Gavroglu (Universidade de Atenas, http://www.gavroglu.gr/) e Ana Simões (Universidade de Lisboa, http://chcul.fc.ul.pt/membros/ana_si moes.htm), são reconhecidos pesquisadores da história da química quântica.

O tema do livro é o que os autores definem como a cultura da química quântica: seus conceitos, suas práticas, suas instituições e os personagens mais importantes que a levaram ao seu status atual. $\mathrm{O}$ ponto de partida do livro é o momento logo após a consolidação da mecânica quântica na segunda metade dos anos 20 do século passado quando químicos e físicos começam a tentar aplicar a nova teoria da estrutura da matéria a problemas químicos, assombrados pela famosa e muito citada frase de Dirac de 1929, um dos fundadores da mecânica quântica: "As leis físicas subjacentes necessárias para a teoria matemática de grande parte da física e da totalidade da química são portanto completamente
Data de publicação na Web: 07 de Maio de 2012 Recebido em 04 de Maio de 2012 Aceito para publicação em 06 de Maio de 2012

conhecidas, e a dificuldade é somente que a aplicação exata destas leis levam a equações muito complicadas para serem solucionadas."

Até o uso extensivo dos computadores digitais a partir do início dos anos 1970, período em que o livro termina, os autores definem com pertinência que a "história da química quântica é a história das tentativas de desenvolver estratégias de como superar o quase autonegado empreendimento para usar mecânica quântica para explicar fenômenos químicos".

Gavrolu e Simões escolheram seis núcleos de questões muito bem articulados entre si para abordar o desenvolvimento da química quântica como disciplina que reúne elementos de química e de física e se tornou uma área do conhecimento em si.

No primeiro núcleo - aspectos epistêmicos - são tratados os múltiplos contextos que estabelecem as fundações para o aparecimento da química quântica, os dilemas dos primeiros praticantes entre um tratamento matemático rigoroso $\mathrm{e}$ uma abordagem semiempírica, os novos conceitos introduzidos e os complexos processos de sua legitimação. A fonte destes dilemas estava na equação de Schrödinger, equação básica da mecânica quântica que só tinha solução analítica - isto é, sem necessidade de aproximações matemáticas - para o átomo de hidrogênio. $O$ consenso atual de que a química quântica é um legítimo campo da química nem sempre existiu na história daquela ciência - ao longo século 20 houve tentativas de apropriação da química quântica tanto pela física como pela matemática aplicada. Os autores argumentam que o desenvolvimento histórico da química quântica tem sido a articulação de sua autonomia relativa 
tanto da física quanto da química, ou seja, como uma área científica per se.

No segundo núcleo - emergência disciplinar - são discutidos alguns aspectos decisivos para a formação do caráter da química quântica. Dentre estes aspectos destacam-se a criação de cátedras, a política universitária, livros-texto, congressos, networking e as alianças que os químicos quânticos buscaram com os praticantes de outras disciplinas. Neste núcleo são destaques as ações de divulgação e propaganda de vários cientistas importantes que contribuíram para a gradual emergência da química quântica como subdisciplina com presença social. Dentre estas ações, há os apelos e trabalhos de Walter Heitler (1904-1981), Fritz London (1900-1954) e Friedrich Hund (18961996) para aplicar a mecânica quântica a problemas químicos e a movimentação incansável de R. S. Mulliken (1896-1986) para familiarizar e propagandear entre químicos e físicos as vantagens da teoria dos orbitais moleculares. São discutidas também a agressividade de Linus Pauling (1901-1994) para estabelecer a teoria da ressonância como a única descrição da química quântica, as tentativas incessantes de Charles Coulson (1910-1974) para popularizar a sua visão do caráter da valência química, as pesquisas de Raymond Daudel (1920-2006) e Bernard (19191996) e Alberte Pullmann (1920- ) em moléculas de interesse biológico e a fundação de uma nova revista científica - "The International Journal of Quatum Chemistry" - por Per-Olov Löwdin (1916 - 2000).

O terceiro núcleo do livro trata do chamado caráter contingente da química quântica. Gavrolu e Simões situam historicamente a maneira como a química quântica chegou ao estado atual. Qual foi o papel que compromissos metodológicos, filosóficos, ontológicos e considerações institucionais tiveram neste processo, e quais foram os percursos que levaram a formação das práticas e culturas da química quântica.
O quarto núcleo trata do impacto do computador eletrônico no início dos anos 1960 nas práticas dos químicos quânticos. Os autores discutem como a dificuldade fundamental da química quântica - a impossibilidade de realizar cálculos sem aproximações matemáticas - é transformada numa vantagem que também contribuiu para o importante e, relativamente desconhecido, papel da química quântica para legitimar $\mathrm{O}$ uso cientifico dos computadores. A promessa dos cálculos $a b$ initio, que não usam dados experimentais em suas equações, fornecer resultados mais confiáveis, se torna mais palpável. Os métodos semiempíricos também se valem do novo paradigma computacional. Nos anos 60 aumenta a complexidade dos problemas moleculares tratados e explode o desenvolvimento de modelos matemáticos e suas respectivas implementações.

Torna-se claro que o progresso da área passa a seguir pari passu o avanço dos computadores. Esta situação, que perdura até hoje, tem uma faceta a ser lamentada: parte não desprezível dos pesquisadores da área vive a esperar avidamente por uma nova versão do seu software preferido para usar as novas funcionalidades, o que resulta em uma grande barreira a dificultar o avanço conceitual da química quântica na descrição e previsão dos fenômenos químicos.

No quinto núcleo os autores tratam de questões da química quântica relacionadas com a filosofia da ciência. Reducionismo, realismo científico, o papel da teoria incluindo seu caráter preditivo e descritivo, o papel de representações pictóricas, a papel de abordagens semiempíricas versus $a b$ initio e o status de entidades teóricas e de observações empíricas. Quase a totalidade dos praticantes da química quântica se preocupou em responder a estas questões filosoficamente e consideraram importante abordar tais problemas como um caminho para estabelecer a química quântica.
No sexto e último núcleo são discutidos os "estilos de raciocínio" da química quântica, em especial como são abordados os problemas da área. Exemplos como a extensão de Mulliken do princípio aufbau de Bohr a moléculas, o estabelecimento dos orbitais moleculares e a abordagem da teoria de ressonância de Pauling são discutidos.

O livro é baseado em pesquisa meticulosa com grande número de referências primárias que são revelações para os praticantes e interessados na área. Livros de anotações de trabalho e correspondências entre os principais personagens foram estudados e ilustram várias discussões no texto. Uma profusão de notas enriquece cada capítulo. O texto tem uma redação cuidadosa e fluente. Dentro da tradição kuhniana de ressaltar a importância e o papel das comunidades de cientistas na história da ciência, Gavrolu e Simões abordam a sociologia dos primeiros grupos de químicos quânticos na Alemanha, na Grã-Bretanha e na França. O desenvolvimento da química quântica é apresentado como uma ilustração da tendência da ciência do século 20 ser caracterizada pelo cruzamento e exploração de fronteiras disciplinares mediadas por novos instrumentos científicos que, no caso da química quântica, é o computador eletrônico digital.

A história dos primeiros cinquenta anos da química quântica desde a sua criação até os anos 70 tem um relato de grande qualidade. O livro é fortemente recomendado aos interessados na história da química, especialmente aos alunos e professores de química quântica. Trechos do livro podem ser lidos no link

http://www.ciuhct.com/index.php/pt/ outras-publicacoes/358-kostassimoes-2011.html.

Documentário "Cientistas Brasileiros: César Lattes \& José Leite Lopes" 2003, Brasil. Dirigido por José Mariani.

\footnotetext{
* Instituto Militar de Engenharia, Departamento de Química, Praça General Tibúrcio, 80, CEP 22290-270, Rio de Janeiro, Brasil.

Mitamar@ime.eb.br
} 